Article

\title{
Rapid and Easy High-Molecular-Weight Glutenin Subunit Identification System by Lab-on-a-Chip in Wheat (Triticum aestivum L.)
}

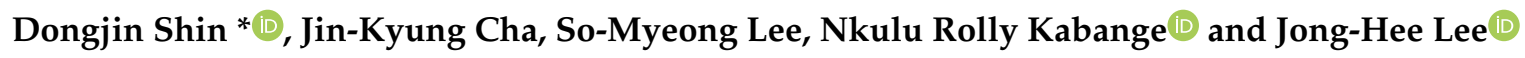 \\ Department of Southern Area Crop Science, National Institute of Crop Science, RDA, Miryang 50424, Korea; \\ jknzz5@korea.kr (J.-K.C.); olivetti90@korea.kr (S.-M.L.); rollykabange@korea.kr (N.R.K.); \\ ccriljh@korea.kr (J.-H.L.) \\ * Correspondence: jacob1223@korea.kr; Tel.: +82-55-350-1185; Fax: +82-55-352-3059
}

Received: 15 October 2020; Accepted: 7 November 2020; Published: 9 November 2020

\begin{abstract}
Lab-on-a-chip technology is an emerging and convenient system to easily and quickly separate proteins of high molecular weight. The current study established a high-molecular-weight glutenin subunit (HMW-GS) identification system using Lab-on-a-chip for three, six, and three of the allelic variations at the Glu-A1, Glu-B1, and Glu-D1 loci, respectively, which are commonly used in wheat breeding programs. The molecular weight of $1 \mathrm{Ax} 1$ and $1 \mathrm{Ax} 2^{*}$ encoded by Glu-A1 locus were of $200 \mathrm{kDa}$ and $192 \mathrm{kDa}$ and positioned below 1Dx subunits. The HMW-GS encoded by Glu-B1 locus were electrophoresed in the following order below $1 \mathrm{Ax} 1$ and $1 \mathrm{Ax2} 2^{*}$ : $1 \mathrm{Bx} 13 \geq 1 \mathrm{Bx} 7=1 \mathrm{Bx} 7^{\mathrm{OE}}>1 \mathrm{Bx} 17>1 \mathrm{By} 16>1 \mathrm{By} 8=1 \mathrm{By} 18>1 \mathrm{By} 9.1 \mathrm{Dx} 2$ and Dx5 showed around 4-kDa difference in their molecular weights, with 1Dy10 and 1Dy12 having 11-kDa difference, and were clearly differentiated on Lab-on-a-chip. Additionally, some of the HMW-GS, including 1By8, 1By18, and 1Dy10, having different theoretical molecular weights showed similar electrophoretic mobility patterns on Lab-on-a-chip. The relative protein amount of $1 \mathrm{~B} \times 7^{\mathrm{OE}}$ was two-fold higher than that of $1 \mathrm{Bx} 7$ or $1 \mathrm{Dx} 5$ and, therefore, translated a significant increase in the protein amount in $1 \mathrm{Bx} 7^{\mathrm{OE}}$. Similarly, the relative protein amounts of $8 \& 10$ and $10 \& 18$ were higher than each subunit taken alone. Therefore, this study suggests the established HMW-GS identification system using Lab-on-a-chip as a reliable approach for evaluating HMW-GS for wheat breeding programs.
\end{abstract}

Keywords: HMW-GS; Lab-on-a-chip; electropherogram; wheat

\section{Introduction}

Wheat (Triticum aestivum L.) is an important staple food crop, which provides substantial amounts of various components, such as proteins and vitamins, that are essential for human consumption and health and the industry. In addition to being an important source of energy, wheat serves as an ingredient for diverse foods due to the presence of the seed storage protein gluten [1], which is built up of subunits and imparts elasticity to a dough [2].

Gluten that affects the end-use quality of common wheat, also known as bread wheat, consists of glutenins and gliadins. The glutenins are protein aggregates divided into high-molecular-weight (HMW-GS, 70 140 kDa) and low-molecular-weight (LMW-GS, 30 50 kDa) subunits [3]. HMW-GS represent approximately $10 \%$ of the total seed storage proteins and critically determine the strength and elasticity of dough with LMW-GS [4].

An x-type and a y-type subunits of HMW-GS encoded in each Glu-1 locus are located on the long arms of chromosome 1 on the A, B, and D genomes of bread wheat [5]. These genes on the Glu-1 loci are tightly linked, considering that the physical distance between an x-type and a y-type subunits ranges 
between 50-180 kb [6]. Six proteins of HMW-GS are translated from three Glu-1 loci. However, some of the HMW-GS proteins are not translated due to gene silencing via elusive mechanisms, and the Glu1-Ay allele is mainly silenced in bread wheat [7]. Therefore, three to five glutenin subunits are found in most bread wheats. The natural allelic diversity for each subunit on the Glu-1 loci was previously reported [8]. The recent development of advanced technologies and analysis equipment allowed the discovery of new allelic forms on the Glu-1 loci from diverse landraces [9]. Reports indicate that endosperm storage proteins encoding genes in wheat are located at nine complex loci on six different chromosomes. Additionally, Glu-A1, Glu-B1, and Glu-D1 possess genes for the high-molecular-weight subunits of glutenins, which are close to the centromeres on the long arms of homologous group-1 chromosomes 1A, 1B, and 1D, respectively [10]. The A subunits, also known as high-molecular-weight (HMW) subunits, are said to be well-resolved by sodium dodecyl sulphate-polyacrylamide gel electrophoresis (SDS-PAGE) [11]. To date, 22 alleles for Glu-A1, 52 for Glu-B1, and 36 for Glu-D1 have been identified [1]. However, some of the alleles at the Glu-1 loci are mainly found in breeding varieties [12]. For instance, Glu-A1a (46.8\%) and Glu-A1c (50.9\%) alleles at the Glu-A1 locus are mainly found in current Chinese commercial wheat cultivars, and two of alleles, Glu-B1b (30.5\%) and Glu-B1c (45.3\%), are abundant at the Glu-B1 locus. In addition, the frequency of the Glu-D1a and Glu-D1d alleles at the Glu-D1 locus are $57.6 \%$ and $41.9 \%$, respectively [13]. Moreover, five alleles, Glu-B1a, Glu-B1b, Glu-B1c, Glu-B1g, and $G l u-B 1 i$, at the Glu-B1 locus are present in Australian wheat cultivars, but the major allele (Glu-B1i) frequency was 35.9\% [14]. The Glu-D1d allele at Glu-D1 was widely used for bread wheat across the globe [15].

The Glu-A1b encoding $1 \mathrm{Ax} 2^{*}$ at Glu-A1 is commonly associated with good dough strength and better bread-making quality [16]. Glu-A1a encoding 1Ax1 at Glu-A1 has been reported to have a high gluten index and a long dough development time compared to Glu-A1b [17]. Several alleles at the Glu-B1 locus have been previously used. Among them, Glu-B1f (encoding the subunit pair 1Bx13 + 1By16) and Glu-B1i (encoding the subunit pair 1Bx17 + 1By18) had a positive effect on the dough rheological properties and bread-making quality, observed through an increase in the gluten content and loaf volume [18]. Previous reports indicated that the transcripts of $1 \mathrm{~B} \times 7^{\mathrm{OE}}$ encoded by Glu-B1al were overexpressed by an insertion of $43 \mathrm{bp}$ in the promoter region and/or gene duplication [19,20]. Glu-B1al was shown to contribute to improving the rheological properties, such as dough strength in hard wheat [21,22]. Similarly, a study by Wang and colleagues [23] revealed that Glu-D1d (encoding the subunit pair 1Dx5 + 1Dy10) at the Glu-D1 locus had a positive effect on the rheological properties and dough quality. Additionally, according to Zhao et al. [22], a combination of Glu-B1al and Glu-D1d improved significantly the bread-making quality, such as dough-mixing time and strength. Some of the Glu-1 alleles that include Glu-A1c (encoding the 1Ax null), Glu-B1d (encoding the subunit pair 1Bx6 + 1By8), and Glu-D1a (encoding the subunit pair 1Dx2 + 1Dy12) have been associated with poor baking quality $[24,25]$. However, the effects of rare alleles that are not used in current breeding cultivars have not been investigated yet.

For several decades, the numbering system based on the mobility of the HMW-GS on sodium dodecyl sulfate-polyacrylamide gel electrophoresis (SDS-PAGE) has been widely employed to identify the allelic variation of HMW-GS [26]. Reverse-phase high-performance liquid chromatography (RP-HPLC) was developed and used to discriminate the allelic variation of HMW-GS [5,27]. In addition, several other methods, such as high-performance capillary electrophoresis (HPCE), matrix-assisted laser desorption/ionization time-of-flight mass spectrometry (MALDI-TOF-MS), and Lab-on-a-chip capillary electrophoresis (Lab-on-a-chip) were applied to identify the composition of HMW-GS [28-31]. Of these methods, MALDI-TOF-MS is said to be appropriate for detecting new allelic variations of HMW-GS [29]. However, SDS-PAGE, RP-HPLC, and MALDI-TOF-MS analysis are time-consuming and require a certain number of processes [32]. In contrast, Lab-on-a-chip has been recognized for being fast and easy to identify and quantify HMW-GS. However, this method is not properly used due to the fact that Lab-on-a-chip has not been completely established, specifically for HMW-GS identification [31]. Interestingly, the protein weight of HMW-GS on Lab-on-a-chip was shown to be 
higher than that observed on SDS-PAGE, and the electrophoresis pattern of HMW-GS on Lab-on-a-chip was different from SDS-PAGE. Useful molecular markers, such as Kompetitive Allele-Specific PCR (KASP) and single-nucleotide polymorphism (SNP) markers, were developed to identify the allelic variation for the Glu-1 loci [32,33]. These molecular markers are useful for the high-throughput identification of allelic variations of genetic resources and the screening of breeding lines for quality improvement [33]. However, they do not have the ability to examine all allelic variations at the same time. Therefore, owing to the above, there is a sustaining need for the development of allelic specific markers for HMW-GS identification [33].

Reports indicate that the annual wheat flour consumption per capita in Korea is about $32 \mathrm{~kg}$, the second largest after rice. However, the self-sufficiency rate is less than 2\%. Developing new cultivars with a good quality for making noodles and bread are required to improve the self-sufficiency rate in Korea. In this study, we established a numbering system of HMW-GS for Lab-on-a-chip to easily identify the HMW-GS in a relatively short time. The newly developed numbering system was verified to be effective and reliable and could be applied in breeding programs.

\section{Results}

\subsection{Identification of $1 A x 1$ and $1 A \times 2 *$ at the Glu-A1 Locus by Lab-on-a-Chip}

The current study established a numbering system for HMW-GS identification with Lab-on-a-chip technology parallel to the widely used SDS-PAGE. We included wheat cultivars with known HMW-GS compositions using standard cultivars (Table 1). These cultivars covered three, six, and three of the allelic variations at the Glu-A1, Glu-B1, and Glu-D1 loci, respectively, which are commonly used in wheat breeding programs. When comparing the electrophoresis patterns of HMW-GS by Lab-on-a-chip, 1Dx2.2 was by default set as the upper marker because of its large size compared to the systematic upper marker $(240 \mathrm{kDa})$. Therefore, the upper marker in the standard cultivars harboring 1Dx2.2, such as Uri and Seodun, was adjusted before analyzing the HMW-GS composition (Figure 1). The recorded molecular weights of HMW-GS on Lab-on-a-chip were above $120 \mathrm{kDa}$ [31].

Table 1. High-molecular-weight glutenin subunit (HMW-GS) composition used as the standard varieties in this study.

\begin{tabular}{cccccccc}
\hline \multirow{2}{*}{ Variety Name } & \multicolumn{5}{c}{ Glu-1 Locus Allele } & \multicolumn{3}{c}{ SDS-PAGE Allele } & \multirow{2}{*}{ Reference } \\
\cline { 2 - 7 } & Glu-A1 & Glu-B1 & Glu-D1 & Glu-A1 & Glu-B1 & Glu-D1 & \\
\hline Jokyung & $a$ & $b$ & $d$ & 1 & $7+8$ & $5+10$ & Jang et al. [5] \\
\hline Keumgang & $b$ & $b$ & $d$ & $2^{*}$ & $7+8$ & $5+10$ & Jang et al. [5] \\
\hline Uri & $c$ & $b$ & $f$ & null & $7+8$ & $2.2+12$ & Jang et al. [5] \\
\hline Petrel & $c$ & $a$ & $d$ & null & 7 & $5+10$ & Liu et al. [34] \\
\hline Seodun & $c$ & $b$ & $f$ & null & $7+8$ & $2.2+12$ & Jang et al. [5] \\
\hline Anbaek & $c$ & $c$ & $a$ & null & $7+9$ & $2+12$ & Jang et al. [5] \\
\hline Joeun & $c$ & $f$ & $f$ & null & $13+16$ & $2.2+12$ & Jang et al. [5] \\
\hline Joongmo2008 & $c$ & $i$ & $d$ & null & $17+18$ & $5+10$ & Jang et al. [5] \\
\hline Vesna & $a$ & $a l$ & $d$ & 1 & 7 OE +8 & $5+10$ & Shin et al. [35] \\
\hline
\end{tabular}




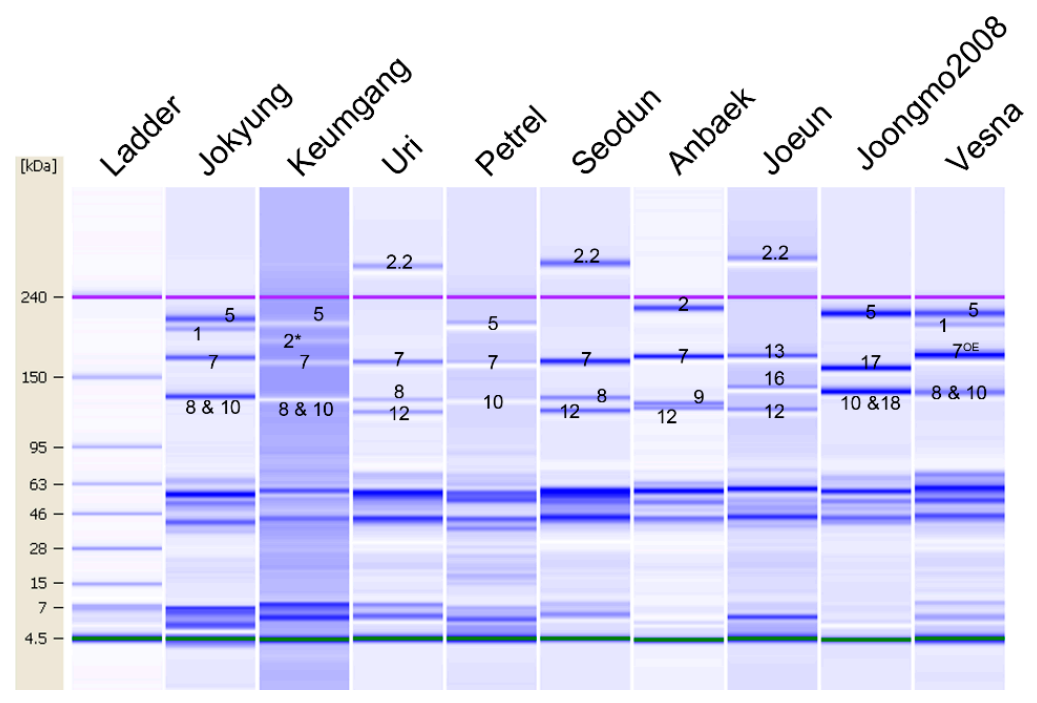

Figure 1. Gel-like image of the standard varieties on Lab-on-a-chip. Six microliters of diluted extracted glutenin proteins with denaturing solution, including in the protein 230 assay kit, were separated by the 2100 Bioanalyzer. The upper marker $(240 \mathrm{kDa})$ was adjusted before analyzing the high-molecular-weight glutenin subunit (HMW-GS) for varieties harboring 1Dx2.2, such as Uri, with the 2100 Expert program. Then, a gel-like image was taken. The purple line indicates the systematic upper marker $(240 \mathrm{kDa})$. The small numbers on the image mean each HMW-GS such as 5 is $1 \mathrm{Dx} 5$ and 1 is $1 \mathrm{Ax} 1$.

To validate the numbering system for the Glu-A1 locus on the Lab-on-a-chip system, we initially compared the observed banding patterns in Jokyung, Keumgang, Uri, and Petrel. Wheat varieties Jokyung and Keumgang harbored the same HMW-GS except at the Glu-1 locus, while Uri and Petrel carried the $1 \mathrm{Ax}$ null subunit on the Glu-A1 locus. In addition, the gel image of Jokyung and Keumgang, which carry the $1 \mathrm{Ax} 1$ and $1 \mathrm{Ax} 2^{*}$ subunits, respectively, showed that only two protein bands of about $200.6 \mathrm{kDa}$ and $192.4 \mathrm{kDa}$ marked the difference between Jokyung and Keumgang (Figure 1 and Figure S1, and Table S1). However, these protein bands could not be found in Uri and Petrel harboring the $1 \mathrm{Ax}$ null subunit. Therefore, these data revealed that the observed protein bands of $200.6 \mathrm{kDa}$ and 192.4 kDa on Lab-on-a-chip are Glu-1Ax1 and Glu-1Ax2*, respectively.

\subsection{Electrophoresis Patterns of HMW-GS Encoded by the Glu-B1 Locus}

In order to validate the electrophoresis banding patterns of HMW-GS encoded by the Glu-B1 locus on Lab-on-a-chip, we used six standard wheat cultivars covering six alleles. To determine the molecular weight of 1Bx7 on Lab-on-a-chip, we first examined the HMW-GS of Petrel, in which the 1Bx7 subunit was only translated from the Glu-B1 locus. The protein band size of $177.8 \mathrm{kDa}$ in Petrel was identified as $1 \mathrm{Bx} 7$ on Lab-on-a-chip, which was similar with the molecular weight of the $1 \mathrm{Bx} 7$ (177 kDa) subunit reported earlier [36]. Additionally, similar protein bands were identified in wheat varieties Seodun and Anbaek, carrying the $1 \mathrm{Bx} 7$ subunit. Meanwhile, Seodun and Anbaek harbored different HMW-GS at the Glu-1B locus, $1 \mathrm{Bx} 7+1 \mathrm{By} 8$ and $1 \mathrm{Bx} 7+1 \mathrm{By} 9$, respectively. When the electrophoresis patterns of HMW-GS in Seodun and Anbaek were compared to one another, $133.9 \mathrm{kDa}$ and $129.9 \mathrm{kDa}$ of the protein bands were detected (Figure 1). A protein band of $133.9 \mathrm{kDa}$ was examined in varieties carrying the 1By8 subunit, such as Jokyung and Uri. Owing to the above, these results suggest that the detected protein band size of $177.8 \mathrm{kDa}$ in Petrel indicates 1Bx7, while the one of $133.9 \mathrm{kDa}$ in Seodun and $129.9 \mathrm{kDa}$ in Anbaek are 1By8 and 1By9, respectively (Figure 1).

The wheat variety Joeun harboring $1 \mathrm{Bx} 13+1 \mathrm{By} 16$ at the Glu-B1 locus was used to establish the electrophoresis pattern of $1 \mathrm{Bx} 13+1 \mathrm{By} 16$. The $171.7 \mathrm{kDa}$ and $141.4 \mathrm{kDa}$ protein bands in Joeun were clearly different compared with Seodun and Anbaek, carrying 1Bx7 + 1By8 and 1Bx7 + 1By9, respectively (Figure 1 and Table S1). The molecular weight of $1 \mathrm{~B} \times 13$ was higher than that of the $1 \mathrm{Bx} 16$ protein observed on SDS-PAGE. Thus, the upper and lower bands in Joeun are considered as 1Bx13 and 
1By16, respectively. The molecular weight of $1 \mathrm{Bx} 13$ is about $1 \mathrm{kDa}$ larger than that of $1 \mathrm{Bx} 7$. The $1 \mathrm{Bx} 13$ protein band was located a little more upper than 1Bx7 on Lab-on-a-chip (Figure 1). Meanwhile, $1 \mathrm{By} 16$ was positioned above 1By8 with 5-kDa difference on Lab-on-a-chip and was clearly distinguished from other HMW-GS.

To determine the position of $1 \mathrm{Bx} 17+1 \mathrm{By} 18$ and $1 \mathrm{Bx} 7^{\mathrm{OE}}+1 \mathrm{By} 8$ on Lab-on-a-chip, we used Joongmo2008 and Vesna possessing $1 \mathrm{Bx} 17+1 \mathrm{By} 18$ and $1 \mathrm{~B} \times 7^{\mathrm{OE}}+1 \mathrm{By} 8$ at the Glu-B1 locus, respectively. The electrophoresis pattern of Joongmo2008 carrying both 1Bx17 + 1By18 was compared with Petrel, which harbors 1Bx7. The molecular weight of the $1 \mathrm{Bx} 17$ protein on Lab-on-a-chip was $159.6 \mathrm{kDa}$ and was clearly differentiated from other subunits (Figure 1). However, we could not distinguish the $1 B y 18$ and 1Dy10 protein bands on Lab-on-a-chip. Nevertheless, the 1Bx17 + 1By18 subunit could be identified using the electrophoresis position of the 1Bx17 subunit from other HMW-GS. In addition, the gel-like image of Vesna harboring $1 \mathrm{Bx} 7^{\mathrm{OE}}+1 \mathrm{By} 8$ was investigated with the purpose of validating the electrophoresis position of $1 \mathrm{Bx} 7^{\mathrm{OE}}+1 \mathrm{By} 8$ (Figure 1). Interestingly, the electrophoresis pattern of $1 \mathrm{Bx} 7^{\mathrm{OE}}+1 \mathrm{By} 8$ on Vesna was the same with Jokyung harboring $1 \mathrm{Bx} 7+1 \mathrm{By} 8$, considering that $1 \mathrm{Bx} 7^{\mathrm{OE}}$ encoded by Glu-B1al are overexpressed by the insertion of $43 \mathrm{bp}$ in the promoter and/or gene duplication of $1 \mathrm{Bx} 7[19,20]$. We could not separate $1 \mathrm{Bx} 7^{\mathrm{OE}}+1 \mathrm{By} 8$ from $1 \mathrm{Bx} 7+1 \mathrm{By} 8$ with the gel-like image of Lab-on-a-chip.

\subsection{Identification of the $1 D x 5+1 D y 10$ Subunit from Other Subunits Encoded from the Glu-D1 Locus}

To validate the electrophoresis pattern of HMW-GS encoded by the Glu-D1 locus, we compared the three kinds of alleles in the Glu-D1 locus: 1Dx2 + 1Dy12, 1Dx5 + 1Dy10, and 1Dx2.2 + 1Dy12. The molecular weights of 1Dx2 in Anbaek, 1Dx5 in Petrel, and 1Dx2.2 in Seodun were 229.0 kDa, $224.0 \mathrm{kDa}$, and 281.7 kDa, respectively (Figure 1 and Table S1). We mentioned earlier that 1Dx2.2 was located above the systemic upper marker $(240 \mathrm{kDa})$. The molecular weight of 1Dy10 in Petrel and 1 Dy12 in Seodun were $133.7 \mathrm{kDa}$ and $123.3 \mathrm{kDa}$, respectively. The data showed that 1Dx subunits encoded by the Glu-D1 locus were positioned above the 1Ax1 and 1Ax2*-encoded Glu-A1 locus, even though the theoretical molecular weight of the 1Dx subunits were smaller than the $1 \mathrm{Ax}$ subunits. The electrophoresis of 1Dy12 on Lab-on-a-chip was faster than the other HMW-GS and was placed at the bottom (Figure 1). When the band sizes of these 1Dx were compared with one another, 1Dx5 was discriminated from 1Dx2. However, it was a bit difficult to distinguish 1Dx2 and 1Dx5, because the molecular weights of these proteins by Lab-on-a-chip were slightly different.

\subsection{Discrimination of $8 \mathcal{E} 10,10 \mathcal{E} 18$, and $7^{O E}$ Subunit by Analyzing the Electropherogram}

HMW-GS were clearly separated by SDS-PAGE. However, some of the HMW-GS were electrophoresed, including the one with the same molecular weight on Lab-on-a-chip: 1By8, 1By18, and 1Dy10. Additionally, the $1 \mathrm{Bx} 7^{\mathrm{OE}}$ subunit showed the same molecular weight with the $1 \mathrm{Bx} 7 \mathrm{subunit}$. Therefore, it is difficult to distinguish subunits clearly with a gel-like image or molecular weights of Lab-on-a-chip (Figure 1, Tables S2 and S3). To distinguish the 1By8 + 1Dy10 (here referred to as $8 \& 10$ ) subunit from 1By8 and 1Dy10, we used three wheat varieties as the background to perform an electrophoresis by Lab-on-a-chip. The results showed that the gel-like image and electropherogram of the 1By8, 1Dy10, and 8 \& 10 subunits had similar protein band positions based on their molecular weights on Lab-on-a-chip (Figure 2 and Table S2). However, the protein amount indicated by the peak height on the electropherogram for 8 \& 10 was about two-fold higher than that of 1By 8 and 1Dy10 taken alone, despite the fact that the band peak height of $1 B x 7$ in Hanbaek carrying 8 \& 10 was slightly lower than the one observed in Saekeumgang and Chapingo (Figure 2). Interestingly, the recorded protein amount indicated by the peak height and relative protein quantity of $8 \& 10$ was about two-fold higher than that of 1Bx7 (Table 2). 
a

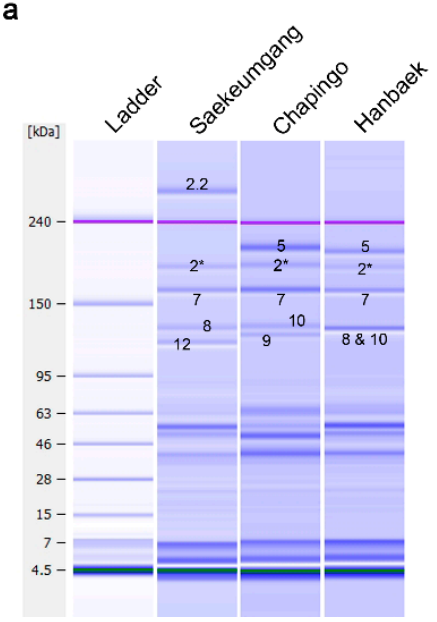

b

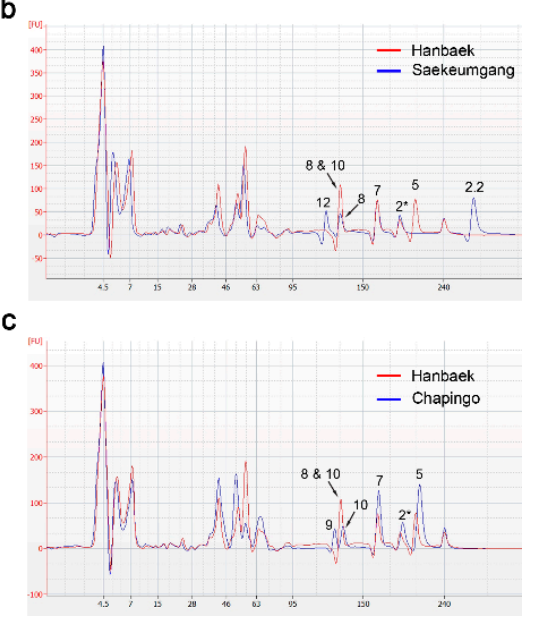

Figure 2. Identification of the 8 \& 10 subunits on Lab-on-a-chip. (a) Gel-like image of HMW-GS. (b) Comparison of the protein quantities between 1 By 8 and $8 \& 10$ by electropherogram. (c) Comparison of the protein quantities between $1 \mathrm{Dy} 10$ and $8 \& 10$ by electropherogram. Six micrograms of diluted extracted glutenin proteins with denaturing solution were separated by the 2100 Bioanalyzer. The electropherograms were overlaid with the 2100 Expert program. The small numbers on the image refer to each HMW-GS, such as 2.2 is $1 \mathrm{Dx} 2.2$ and 12 is $1 \mathrm{Dy} 12$.

Table 2. The relative protein quantity of HMW-GS for 8 \& 10 identification by Lab-on-a-chip. The relative protein quantity of each HMW-GS was analyzed by the band peak area on an electropherogram. Three independent experiments were performed. Data are mean values $(\%) \pm S D$.

\begin{tabular}{cccc}
\hline HMW-GS & Saekeumgang & Chapingo & Hanbaek \\
\hline 1Ax2* & $11.5 \pm 2.68$ & $13.7 \pm 1.26$ & $11.0 \pm 0.98$ \\
1Dx5 & - & $33.7 \pm 3.29$ & $34.3 \pm 5.11$ \\
1Dx2.2 & $23.7 \pm 5.08$ & - & - \\
1Bx7 & $31.3 \pm 5.56$ & $27.5 \pm 1.85$ & $25.8 \pm 1.63$ \\
1By8 & $13.1 \pm 3.29$ & - & - \\
1By9 & - & $9.9 \pm 1.98$ & - \\
8 \& 10 & - & - & $29.0 \pm 5.28$ \\
1Dy10 & - & $15.2 \pm 3.04$ & - \\
1Dy12 & $20.4 \pm 5.49$ & - & - \\
\hline
\end{tabular}

Additionally, the discrimination of the 1By18 + 1Dy10 (referred to as 10\&18) and 1Dy10 protein bands indicated in the electropherogram of Chapingo and Garnet, which harbor 1 Dy 10 and 10 \& 18 , respectively, revealed that the protein amount of 10 \& 18 was about two-fold higher than that of 1 Dy10 alone (Table 3). Meanwhile, the band peak height of $1 \mathrm{Ax} 2 *$ and 1Dx5 showed similar patterns (Figure 3). Furthermore, $8 \& 10$ and $10 \& 18$ exhibited similar protein amounts (Figure 3 ). Thus, it is believed that, when $8 \& 10$ and $10 \& 18$ are electrophoresed together on Lab-on-a-chip, these subunits could be distinguished by analyzing the relative protein amounts on an electropherogram (Figure 3 and Table 3).

Besides, the $1 \mathrm{~B} \times 7^{\mathrm{OE}}+1 \mathrm{By} 8$ subunit was identified on Lab-on-a-chip in nine wheat varieties that carry similar HMW-GS, without $1 \mathrm{Bx} 7$ or $1 \mathrm{~B} \times 7^{\mathrm{OE}}$. The results indicated that all the selected varieties exhibited a similar electrophoresis pattern on the gel-like image, but $1 \mathrm{Bx} 7 \mathrm{OE}^{\mathrm{OE}}$ showed a high band density compared to that of the other HMW-GS (Figure 4). The analysis of the electropherogram of the nine wheat varieties showed that $1 \mathrm{Bx} 7^{\mathrm{OE}}$ had peak heights of about two-fold higher than those of $1 \mathrm{Dx} 5$ or $8 \& 10$ (Figure S2 and Table S4). Despite the fact that $1 \mathrm{Bx} 7^{\mathrm{OE}}$ and $1 \mathrm{Bx} 7$ showed similar protein sizes on Lab-on-a-chip, $1 \mathrm{Bx} 7^{\mathrm{OE}}$ could be distinguished from $1 \mathrm{Bx} 7$ by its protein amount (thick band) on the gel-like image and relative protein amount on the electropherogram in Lab-on-a-chip. 
Table 3. Relative protein quantity of HMW-GS for 10 \& 18 identification by Lab-on-a-chip. The relative protein quantity of each HMW-GS was analyzed by the band peak area on the electropherogram. Three independent experiments were performed. Values are the mean $(\%) \pm S D$.

\begin{tabular}{ccccc}
\hline HMW-GS & Chapingo & Garnet & Vesna & MK4060 \\
\hline 1Ax1 & - & - & $9.5 \pm 1.12$ & - \\
1Ax2* & $13.7 \pm 1.26$ & $6.4 \pm 0.34$ & - & $9.8 \pm 1.12$ \\
1Bx7 & $27.5 \pm 1.85$ & - & - & - \\
1Bx17 & - & $30.2 \pm 0.94$ & - & $30.2 \pm 2.62$ \\
1Bx7 $0 E$ & - & - & $45.3 \pm 2.71$ & - \\
$1 \mathrm{By} 9$ & $9.9 \pm 1.98$ & - & - & - \\
$8 \& 10$ & - & - & $20.4 \pm 1.28$ & \\
$10 \& 18$ & - & $29.2 \pm 4.25$ & - & $28.9 \pm 2.15$ \\
1Dx5 & $33.7 \pm 3.29$ & $34.3 \pm 3.11$ & $24.8 \pm 1.06$ & $31.1 \pm 0.96$ \\
1Dy10 & $15.2 \pm 3.04$ & - & - & - \\
\hline
\end{tabular}

a

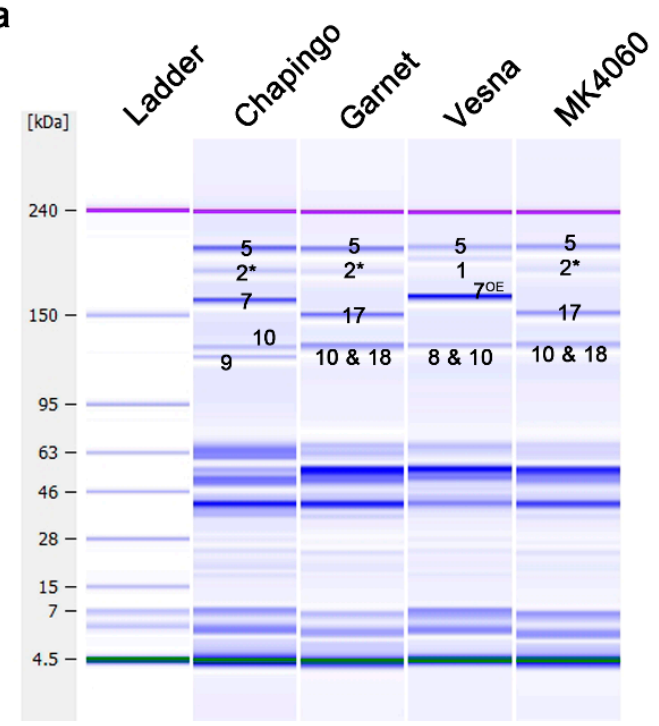

b

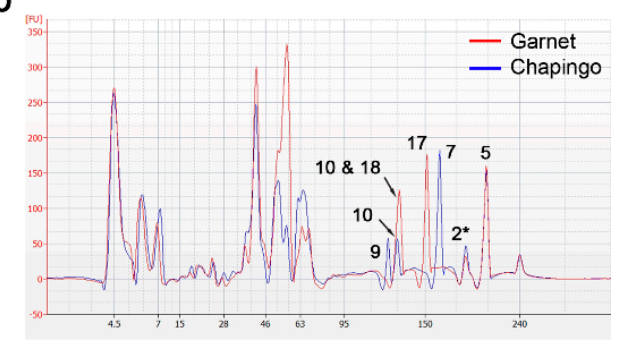

C

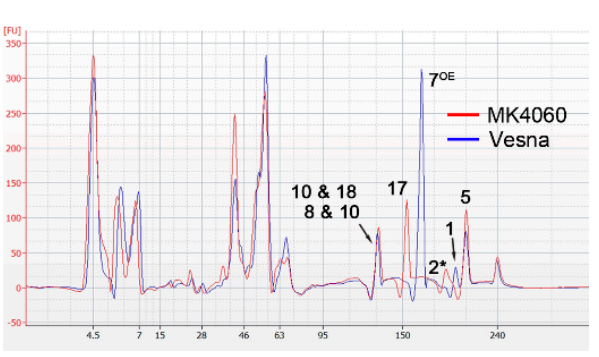

Figure 3. Identification of the $10 \& 18$ subunit on Lab-on-a-chip. (a) The gel-like image of HMW-GS. (b) Comparison of the protein quantities between 1 Dy10 and $10 \& 18$ by electropherogram. (c) Comparison of the protein quantities between $8 \& 10$ and 10 \& 18 by electropherogram. Six micrograms of diluted extracted glutenin proteins with denaturing solution were separated by the 2100 Bioanalyzer. The electropherograms were overlaid with the 2100 Expert program. The small numbers on the image mean each HMW-GS, such as 5 is $1 \mathrm{Dx} 5$ and $2^{*}$ is $1 \mathrm{Ax} 2^{*}$.

\subsection{HMW-GS Composition Identification of Genetic Resources by Lab-on-a-Chip}

To examine whether the established numbering system with Lab-on-a-chip could be effectively used for HMW-GS identification in a wheat breeding program, we tested the HMW-GS of 121 varieties by both the gel-like image and electropherogram of Lab-on-a-chip. The data showed that 1Ax1, $1 \mathrm{Ax2} 2^{*}$, and $1 \mathrm{Ax}$ null at the Glu-A1 locus were found in 51,56, and 14 verities with their respective molecular weights on Lab-on-a-chip of $201.5 \mathrm{kDa}$ and $191.8 \mathrm{kDa}$ (Figure 5). Of all the HMW-GS at the Glu-B1 locus, the $1 \mathrm{Bx} 7+1 \mathrm{By} 9$ or $1 \mathrm{Bx} 17+1 \mathrm{By} 18$ subunits were detected at a high frequency compared to the composition of the other subunits. In essence, 34 varieties carried the $1 \mathrm{Bx} 7+1 \mathrm{By} 9$ subunit, while the $1 \mathrm{Bx} 13+1 \mathrm{By} 16$ and $1 \mathrm{~B} \times 7^{\mathrm{OE}}+1 \mathrm{By} 8$ subunits were found in 10 and 18 varieties, respectively. However, no variety carried an independent $1 B \times 7$ subunit. The average molecular weight of these subunits encoded by the Glu-B1 locus ranged from 125.9-168.9 kDa on Lab-on-a-chip (Tables S5 and S6). Whereas $1 \mathrm{Bx} 7$ and $1 \mathrm{Bx} 7^{\mathrm{OE}}$ exhibited an average molecular weight of $166.6 \mathrm{kDa}$ and $166.8 \mathrm{kDa}$, and $1 \mathrm{Bx} 13$ and $1 \mathrm{Bx} 17$ showed $168.9 \mathrm{kDa}$ and $153.9 \mathrm{kDa}$, respectively. Subunits 1By8, 1By9, 
1By16, and 1By18 had $133.7 \mathrm{kDa}, 125.9 \mathrm{kDa}, 139.3 \mathrm{kDa}$, and $133.9 \mathrm{kDa}$, respectively. Moreover, 105, 3 , and 13 of varieties harbored the 1Dx5 + 1Dy10, 1Dx2 + 1Dy12, and 1Dx2.2 + 1Dy12 encoded by the Glu-D1 locus. The average molecular weights of 1Dx5, 1Dx2, and 1Dx2.2 on Lab-on-a-chip were $210.8 \mathrm{kDa}, 218.0 \mathrm{kDa}$, and $277.3 \mathrm{kDa}$, while the ones of $1 \mathrm{Dy} 10$ and $1 \mathrm{Dy} 12$ were $133.2 \mathrm{kDa}$ and $122.4 \mathrm{kDa}$, respectively (Figure 5).

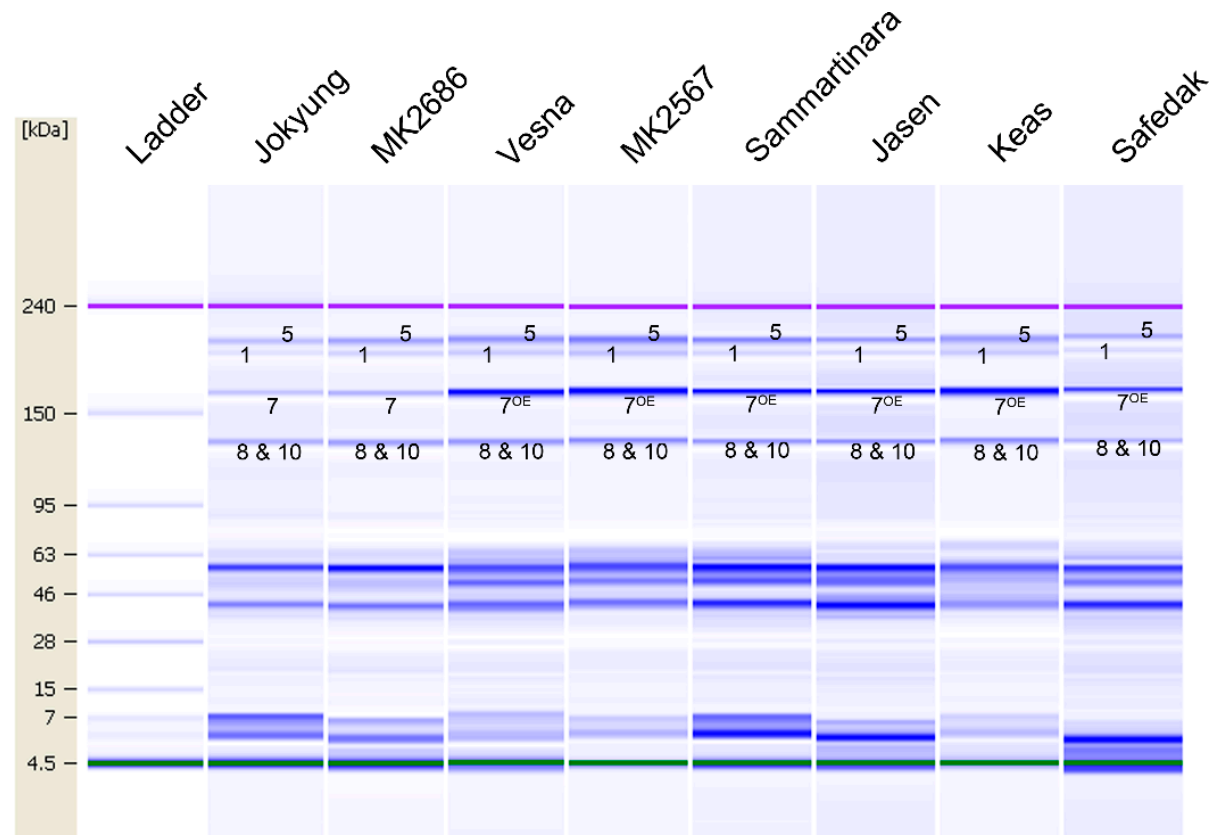

Figure 4. Identification of the $7^{\mathrm{OE}}$ subunit on Lab-on-a-chip. Gel-like image of HMW-GS in different wheat varieties. The small numbers on the image mean each HMW-GS, such as 7 is $1 \mathrm{Bx} 7$ and $7 \mathrm{OE}$ is $1 \mathrm{~B} \times 7^{\mathrm{OE}}$.

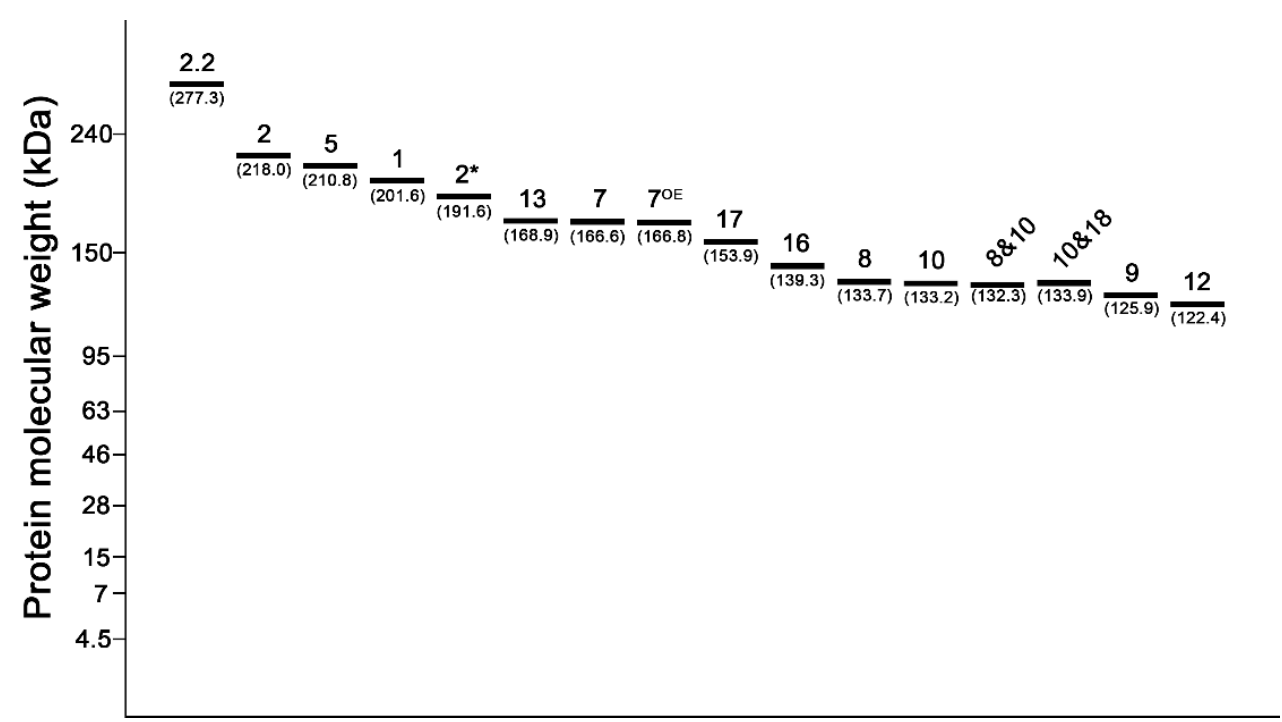

Figure 5. Molecular weights of HMW-GS on Lab-on-a-chip. The mean of each HMW-GS was calculated by analyzing of molecular weight of each HMW-GS from the genetic resources. The small numbers on the image mean each HMW-GS, such as 2 is $1 \mathrm{D} \times 2$ and 5 is $1 \mathrm{Dx} 5$. 


\section{Discussion}

Recent decades have been marked by significant progress in the genetic characterization of gluten proteins in wheat using improved procedures or methods of protein fractionation and the higher availability of genetic resource stocks.

The Lab-on-a-chip electrophoresis system is a reliable and efficient technology for fast and easy protein separation and quantification. In addition, Lab-on-a-Chip equipment offers the unique comparative advantage of being deployable beyond the laboratory compared to conventional methods of protein analysis. However, it still needs to be established for the HMW-GS identification for wheat breeding. Earlier, a study conducted by Rhazi et al. [37] investigated the separation and quantification of HMW-GS in wheat using a high-throughput microchip capillary electrophoresis-sodium dodecyl sulfate (microchip CE) platform, the LabChip 90 system. Their study proposed that the microchip CE analysis could provide a comparable resolution and sensitivity to conventional RP-HPLC for the identification of HMW-GS but faster compared to the latter. In the same way, Uthayakumaran and his colleagues $[38,39]$ proposed a similar separation and identification system of HWM-GS with a longer sample processing time using an Agilent 2100 Bioanalyzer with a Protein $200+$ LabChip.

In addition, other studies have established a numbering system for HMW-GS identification by SDS-PAGE, based on the molecular weight of HMW-GS [5]. The HMW-GS were named by electrophoresis mobility on SDS-PAGE, and this system has been used for HMW-GS identification for years [2]. However, the HMW-GS identification system by SDS-PAGE was shown to be time-consuming and required a large gel system to clearly separate HMW-GS. Many research groups have tried to apply the Lab-on-a-chip system for HMW-GS identification, due to the fast and effective protein separation and quantification that offers the Lab-on-a-chip electrophoresis system [31,40]. However, the latter system is not commonly used for HMW-GS identification due to particular reasons [31]. On the one hand, the molecular weight of HMW-GS on Lab-on-a-chip was shown to be higher than that observed on SDS-PAGE [31].

In the current study, we distinguished and validated the exact molecular weights and quantified each HMW-GS on Lab-on-a-chip using standard wheat varieties and other genetic resources. On the one hand, the theoretical molecular weight of HMW-GS ranged between 70-150 kDa, but the molecular weights investigated in standard varieties and genetic resources on Lab-on-a-chip ranged between $120-280 \mathrm{kDa}$ (Figure 5). On the other hand, the electrophoresis patterns of $1 \mathrm{Ax} 1$ and $1 \mathrm{Ax2}{ }^{*}$ on the Lab-on-a-chip system were found to be different from the one on SDS-PAGE. The 1Ax1 and $1 \mathrm{Ax} 2^{*}$ subunits were detected above the 1Dx2 and 1Dx5 subunits in SDS-PAGE, considering its theoretical molecular weight. However, these subunits were positioned below the 1Dx2 and 1Dx5 subunits on Lab-on-a-chip (Figure 1) [2,40]. It has been reported that Tris-acetate acrylamide gel is ideal for separating large-molecular-weight proteins. In our previous study, when HMW-GS proteins were electrophoresed in 3-8\% of gradient Tris-acetate acrylamide gel on SDS-PAGE, the 1Ax1 and $1 \mathrm{Ax} 2^{*}$ proteins were detected at a lower position than Dx2 and Dx5 in this gel condition like Lab-on-a-chip [35]. This phenomenon was also observed when acid polyacrylamide gel (A-PAGE) was applied for HMW-GS separation [30]. In addition, the 1Dy10 subunit was clearly separated from the 1By8 and 1By18 subunits on SDS-PAGE. The application of another Lab-on-a-chip system, the Experion Pro 260 assay kit (Bio-Rad, Hercules, CA, USA), revealed that the electrophoresis patterns of HMW-GS were different from those observed with a Protein 230 assay kit (Agilent Technologies, Palo Alto, CA, USA). The 1Dy10 protein was discriminated from 1Bx8, but $1 \mathrm{Bx} 8$ was found to overlap with 1Dy12 in the Experion Pro 260 assay kit [41]. We did not find the main reason for the 1Dy10 subunit to be slowly electrophoresed on Lab-on-a-chip with the Protein 230 assay kit. However, it is thought that it could be due to the buffer and gel system of the Protein 230 assay kit for Lab-on-a-chip. The 240-kDa protein considered as a systemic upper marker is used to determine the protein molecular weight on Lab-on-a-chip. Any protein that could be detected in the sample having a larger size than the upper marker was, by default, set as the systemic upper marker. The molecular weight of 1Dx2.2 
on Lab-on-a-chip was higher than the systemic upper marker, which led to the adjustment of the systemic upper marker position prior to analyzing the HMW-GS composition (Figure 1).

Jang et al. [5] evaluated the HMW-GS composition wheat varieties, and they used 16 standard wheat varieties for HMW-GS identification and 38 Korean wheat cultivars by RP-HPLC and SDS-PAGE [5]. In our case, to establish the HMW-GS identification in the wheat breeding program on Lab-on-a-chip, we used nine varieties of which the HMW-GS were identified earlier [5]. We then screened Vesna carrying $1 \mathrm{Bx} 7^{\mathrm{OE}}$ by the Kompetitive allele-specific PCR (KASP) assay with the Bx $7^{\mathrm{OE}}$ _866_SNP marker and later used it for $1 \mathrm{Bx} 7^{\mathrm{OE}}$ subunit identification [35]. These varieties covered three, six, and three allelic variations at the Glu-A1, Glu-B1, and Glu-D1 loci, respectively (Figure 1). They did not cover all allelic variations of the $\mathrm{Glu}-1$ loci, but we thought that the allelic variations used in this study were enough to be applied in wheat breeding programs. In the present study, four varieties were used to specify the molecular weight of $1 \mathrm{Ax} 1,1 \mathrm{Ax} 2^{*}$, and $1 \mathrm{Ax}$ null encoded by the Glu-A1 locus. We first found $1 \mathrm{Ax} 1$ of Jokyung and $1 \mathrm{Ax} 2^{*}$ of Keumgang by excluding the same positional proteins after comparing with Uri and Petrel harboring the $1 \mathrm{Ax}$ null. The molecular weights of $1 \mathrm{Ax} 1$ and $1 \mathrm{Ax} 2^{*}$ were lower than 1Dx2 and 1Dx5 on Lab-on-a-chip (Figure 1) [31,41]. Previously, diverse alleles were reported in the Glu-B1 locus. We determined the molecular weight and relative quantity of six alleles in the Glu-B1 locus on Lab-on-a-chip [42]. The molecular weight of HMW-GS encoded by the Glu-Bl locus was shown in the following order: $1 \mathrm{Bx} 13 \geq 1 \mathrm{Bx} 7=1 \mathrm{~B} \times 7^{\mathrm{OE}}>1 \mathrm{Bx} 17>1 \mathrm{By} 16>1 \mathrm{By} 8=1 \mathrm{By} 18$ $>1 \mathrm{By} 9$. The molecular weight of $1 \mathrm{Bx} 13$ was slightly higher than that of $1 \mathrm{Bx} 7$ and $1 \mathrm{Bx} 7{ }^{\mathrm{OE}}$, and the electrophoresis mobility of 1By8 was similar with 1By18 on Lab-on-a-chip.

However, $x$-type and y-type HMW-GS moved like one gene, because the physical distance between these genes was about 50 180 kb [7]. So, the 1Bx7 + 1By8, 1Bx7 + 1By9, 1Bx13 + 1By16, and 1Bx17 + $1 \mathrm{By} 18$ compositions were discriminated using the molecular weights of $1 \mathrm{By} 8,1 \mathrm{By} 9,1 \mathrm{By} 16$, and 1Bx17, respectively (Figure 5). Additionally, the composition of $1 \mathrm{~B} x 7+1 \mathrm{By} 8$ was effectively separated from other HMW-GS by investigating the relative protein quantity on an electropherogram of Lab-on-a-chip (Table S1).

In the case of HMW-GS on the Glu-D1 locus, 1Dx2.2 + 1Dy12 was clearly observed, and this was facilitated by the position of 1Dx2.2 above the systematic upper marker. The molecular weight of 1Dx2 was $7 \mathrm{kDa}$ higher than 1Dx5, though, in similar cases, it was not always easy to distinguish $1 \mathrm{Dx} 2$ from 1Dx5 on Lab-on-a-chip. However, 1Dy12 was faster electrophoresed than 1Dy10. Thus, 1Dx2 + 1Dy12 and 1Dx5 + 1Dy10 were identified by examining 1Dy12 on a gel-like image of Lab-on-a-chip (Figure 1).

Subunits 1By8 and 1Dy10 were clearly differentiated by Lab-on-a-chip with the Experion Pro 260 assay kit [41]. Three of the HMW-GS, 1By8, 1By18, and 1Dy10, were electrophoresed as having similar molecular weights on the Lab-on-a-chip with the Protein 230 assay kit (Figures 2 and 3). It is then believed that the difference between the Experion Pro 260 assay kit and Protein 230 assay kit of Agilent could be partly explained by different buffer systems for Lab-on-a-chip. Despite the existing differences in the protein electrophoresis mobility of HMW-GS between manufacturers, the $8 \& 10$ and $10 \& 18$ bands could be distinguished from 1By8, 1By18, and 1Dy10 alone by analyzing the relative protein quantity of the electropherogram (Figures 2 and 3). Additionally, no reports could be found elaborating on the electropherogram analysis to identify HMW-GS currently, but the electropherogram analysis was found to be an important way for clear HMW-GS identification, such as 8 \& 10 .

Besides, the reported molecular markers were useful for high-throughput HMW-GS identification, and KASP assay makers for HMW-GS identification were recently developed for rapid genotyping [33,35]. However, it still requires independent experiments for each HMW-GS. Lab-on-a-chip takes about 25 min to process 10 samples for HMW-GS identification, and approximately 120 samples could be tested in a day [31]. All HMW-GS could be identified and quantified at the same time. Therefore, this study established an HMW-GS identification system for Lab-on-a-chip, with standard varieties covering diverse HMW-GS. The Lab-on-a-chip system is relatively easier and faster than SDS-PAGE and RP-HPLC. Nevertheless, downstream studies are required to validate for minor alleles of HMW-GS. Owing to the above, this study suggests that the Lab-on-a-chip system 
could be served as a reliable and effective technology to identify and quantify the HMW-GS for the wheat breeding program.

\section{Materials and Methods}

\subsection{HMW-GS Composition Identification of Genetic Resources by Lab-on-a-Chip}

Nine wheat varieties covering diverse HMW-GS were used to develop the numbering system for the HMW-GS identification by Lab-on-a-chip (Table 3). These varieties included three alleles at the Glu-A1 locus, six alleles at the Glu-B1 locus, and three alleles at the Glu-D1 locus. Three, four, and eight varieties were used to evaluate the protein amounts of $8 \& 10,10 \& 18$, and $7^{\mathrm{OE}}$ subunits, respectively, on an electropherogram. Another set of 121 wheat varieties were obtained from the National Agrobiodiversity Center, National Institute of Agricultural Science, Rural Development Administration (RDA), Republic of Korea. These varieties were used to examine and verify the efficiency and reliability of the newly developed numbering system for HMW-GS identification.

The glutenin was extracted from wheat flour following the procedure reported by Van Den Broeck et al. [43]. Briefly, a mixture of approximately $100 \mathrm{mg}$ of flour and $1 \mathrm{~mL}$ of $50 \%$ $(v / v)$ propanol was incubated for $30 \mathrm{~min}$ at $65{ }^{\circ} \mathrm{C}$, followed by centrifugation at $10,000 \times g$ for $5 \mathrm{~min}$, and the supernatant containing gliadin was discarded. Then, the precipitate was suspended in $0.7-\mathrm{mL}$ 80-mM Tris- $\mathrm{HCl}(\mathrm{pH} 8.0)$ containing $2 \%$ SDS and $1 \%(w / v)$ dithiothreitol (DTT) and incubated at $65^{\circ} \mathrm{C}$ for $30 \mathrm{~min}$. The mixture was centrifuged at $10,000 \times \mathrm{g}$ for $5 \mathrm{~min}$, and $0.3 \mathrm{~mL}$ of the buffer containing $1 \%$ DTT was added and incubated at $65^{\circ} \mathrm{C}$ for $15 \mathrm{~min}$. After centrifugation at $10,000 \times g$ for $5 \mathrm{~min}$, the supernatant was collected and used for downstream analysis by Lab-on-a-chip.

The Protein 230 assay kit (Agilent Technologies, Palo Alto, CA, USA) was used for HMW-GS identification. A total of $12 \mu \mathrm{g}(3 \mu \mathrm{g} / \mu \mathrm{L})$ of extract glutenin proteins were mixed with $2 \mu \mathrm{L}$ of denaturing solution. After heating at $95{ }^{\circ} \mathrm{C}$ for $5 \mathrm{~min}, 84 \mu \mathrm{L}$ of deionized water was added to the sample tube. Six microliters of diluted samples were loaded on the chip. Then, the diluted samples were separated on the 2100 Bioanalyzer (Agilent Technologies, Palo Alto, CA, USA), based on gel electrophoresis principles replicated onto a chip format following the manufacturer's instructions [44]. The upper marker $(240 \mathrm{kDa})$ was adjusted before analyzing the HMW-GS for varieties harboring 1Dx2.2. The protein concentration was quantified with electropherogram on the 2100 Expert program (Agilent Technologies, Palo Alto, CA, USA). Samples were collected in triplicate for each wheat variety used in the study. The values of protein amounts obtained from different band picks were compared using the Student's $t$-test $(p<0.05)$.

\subsection{Glutenin Proteins Extraction and HMW-GS Composition Identification of Genetic Resources by SDS-PAGE}

Glutenin subunits were also separated by sodium dodecyl sulfate-polyacrylamide gel electrophoresis (SDS-PAGE) following the procedure described earlier [45]. Briefly, the separation gel contained 1.5-M Tris-HCl ( $\mathrm{pH} 8.8)$ and $0.27 \%$ SDS. Gels were made of $7.5 \%(w / v)$ acrylamide and $0.2 \%$ $(w / v)$ bis-acrylamide. The stacking gel was made of $0.25-\mathrm{M}$ Tris- $\mathrm{HCl}(\mathrm{pH} 6.8), 0.2 \%$ SDS, and $7.5 \%(w / v)$ acrylamide and $0.2 \%(w / v)$ bis-acrylamide. Wheat flour was suspended in $300-\mathrm{mL} 0.25-\mathrm{M}$ Tris-HCl buffer (pH 6.8), containing $2 \%(w / v)$ SDS, $10 \%(v / v)$ glycerol, and 5\% 2-mercaptoethanol, followed by shaking for $2 \mathrm{~h}$ at room temperature. Then, the slurry was heated for $3 \mathrm{~min}$ at $95{ }^{\circ} \mathrm{C}$, and the supernatant was subjected to SDS-PAGE.

The HMW numbering system of glutenin subunit bands and that for the allelic classification at different loci previously proposed by Payne and his colleague [11] were used in the current study. For the determination of the electrophoretic mobility of each HMW glutenin subunit by SDS-PAGE, standard wheat varieties that included the spectra of the subunits expected were used. Thus, the overall quality scores of HMW glutenin subunits for a particular variety could be obtained as the sum of the 
scores of each individual subunit and compared with the standard bread-making quality of the wheat varieties [46].

Supplementary Materials: The following are available online at http:/www.mdpi.com/2223-7747/9/11/1517/s1. Figure S1: The electropherogram of the standard varieties on Lab-on-a-chip. Figure S2: Comparison of the electropherogram of the $7^{\mathrm{OE}}$ subunit by Lab-on-a-chip. Table S1: Molecular weight and relative protein quantity of the standard varieties by Lab-on-a-chip. Table S2: Molecular weight of HMW-GS for 8 \& 10 identification by Lab-on-a-chip. Table S3: Molecular weight of HMW-GS for 10 \& 18 identification by Lab-on-a-chip. Table S4: Molecular weight and relative protein quantity of HMW-GS for $7 \mathrm{OE}^{\mathrm{OE}}$ identification by Lab-on-a-chip.

Author Contributions: Conceptualization, D.S. and J.-H.L.; formal analysis, D.S.; investigation, J.-K.C. and S.-M.L.; writing-review and editing, D.S. and N.R.K.; and supervision, D.S. All authors have read and agreed to the published version of the manuscript.

Funding: This work was supported by a grant from the National Institute of Crop Science, the Rural Development Administration, Korea (PJ01356401).

Conflicts of Interest: The authors declare no conflict of interest.

\section{References}

1. Zhang, Y.; Hu, M.; Liu, Q.; Sun, L.; Chen, X.; Lv, L.; Liu, Y.; Jia, X.; Li, H. Deletion of high-molecular-weight glutenin subunits in wheat significantly reduced dough strength and bread-baking quality. BMC Plant Biol. 2018, 18, 319. [CrossRef] [PubMed]

2. Payne, P.I. Genetics of wheat storage proteins and the effect of allelic variation on bread-making quality. Annu. Rev. Plant Physiol. 1987, 38, 141-153. [CrossRef]

3. Gao, L.; Ma, W.; Chen, J.; Wang, K.; Li, J.; Wang, S.; Bekes, F.; Appels, R.; Yan, Y. Characterization and comparative analysis of wheat high molecular weight glutenin subunits by SDS-PAGE, RP-HPLC, HPCE, and MALDI-TOF-MS. J. Agric. Food Chem. 2010, 58, 2777-2786. [CrossRef] [PubMed]

4. Liu, H.; Wang, K.; Xiao, L.; Wang, S.; Du, L.; Cao, X.; Zhang, X.; Zhou, Y.; Yan, Y.; Ye, X. Comprehensive Identification and Bread-Making Quality Evaluation of Common Wheat Somatic Variation Line AS208 on Glutenin Composition. PLoS ONE 2016, 11, e0146933. [CrossRef] [PubMed]

5. Jang, Y.R.; Beom, H.R.; Altenbach, S.B.; Lee, M.K.; Lim, S.H.; Lee, J.Y. Improved Method for Reliable HMW-GS Identification by RP-HPLC and SDS-PAGE in Common Wheat Cultivars. Molecules 2017, 22, 1055. [CrossRef] [PubMed]

6. Xiang, L.; Huang, L.; Gong, F.; Liu, J.; Wang, Y.; Jin, Y.; He, Y.; He, J.; Jiang, Q.; Zheng, Y.; et al. Enriching LMW-GS alleles and strengthening gluten properties of common wheat through wide hybridization with wild emmer. 3 Biotech 2019, 9, 355. [CrossRef] [PubMed]

7. Luo, G.; Song, S.; Zhao, L.; Shen, L.; Song, Y.; Wang, X.; Yu, K.; Liu, Z.; Li, Y.; Yang, W. Mechanisms, origin and heredity of Glu-1Ay silencing in wheat evolution and domestication. Theor. Appl. Genet. 2018, 131,1561-1575. [CrossRef] [PubMed]

8. Nakamura, H.; Inazu, A.; Hirano, H. Allelic variation in high-molecular-weight glutenin subunit loci of Glu-1 in Japanese common wheats. Euphtica 1999, 106, 131-138. [CrossRef]

9. Geisslitz, S.; America, A.H.; Scherf, K.A. Mass spectrometry of in-gel digests reveals differences in amino acid sequences of high-molecular-weight glutenin subunits in spelt and emmer compared to common wheat. Anal. Bioanal. Chem. 2020, 412, 1277-1289. [CrossRef]

10. Jackson, E.A.; Holt, L.M.; Payne, P.I. Characterisation of high molecular weight gliadin and low-molecular-weight glutenin subunits of wheat endosperm by two-dimensional electrophoresis and the chromosomal localisation of their controlling genes. Theor. Appl. Genet. 1983, 66, 29-37. [CrossRef]

11. Payne, P.I.; Holt, L.M.; Lawrence, G.J.; Law, C.N. The genetics of gliadin and glutenin, the major storage proteins of the wheat endosperm. Plant Foods Hum. Nutr. 1982, 31, 229-241. [CrossRef]

12. Yasmeen, F.; Khurshid, H.; Ghafoor, A. Genetic divergence for high-molecular weight glutenin subunits (HMW-GS) in indigenous landraces and commercial cultivars of bread wheat of Pakistan. Genet. Mol. Res. 2015, 14, 4829-4839. [CrossRef] [PubMed]

13. Gao, S.; Sun, G.; Liu, W.; Sun, D.; Peng, Y.; Ren, X. High-molecular-weight glutenin subunit compositions in current Chinese commercial wheat cultivars and the implication on Chinese wheat breeding for quality. Cereal Chem. 2020, 97, 762-771. [CrossRef] 
14. Fu, X.; Jia, D.; Li, M.; He, M.; Shi, Z.; Cai, X.; Guo, J. Composition analysis of HMW-GS in Australian wheat cultivars. Hunan Agric. Sci. Technol. 2011, 12, 1010-1012.

15. Zheng, W.; Li, S.; Liu, Z.; Zhou, Q.; Feng, Y.; Chai, S. Molecular marker assisted gene stacking for disease resistance and quality genes in the dwarf mutant of an elite common wheat cultivar Xiaoyan22. BMC Genet. 2020, 21, 45. [CrossRef]

16. Vázquez, D.; Berger, A.G.; Cuniberti, M.; Bainotti, C.; de Miranda, M.Z.; Scheeren, P.L.; Jobet, C.; Zúñiga, J.; Cabrera, G.; Verges, R. Influence of cultivar and environment on quality of Latin American wheats. J. Cereal Sci. 2012, 56, 196-203. [CrossRef]

17. Tabiki, T.; Ikeguchi, S.; Ikeda, T.M. Effects of high-molecular-weight and low-molecular-weight glutenin subunit alleles on common wheat flour quality. Breed. Sci. 2006, 56, 131-136. [CrossRef]

18. Guo, H.; Wu, J.; Lu, Y.; Yan, Y. High-Molecular-Weight Glutenin 1Bx17 and 1By18 Subunits Encoded by Glu-B1i Enhance Rheological Properties and Breadmaking Quality of Wheat Dough. J. Food Qual. 2019, 2019, 1958747. [CrossRef]

19. Ragupathy, R.; Naeem, H.A.; Reimer, E.; Lukow, O.M.; Sapirstein, H.D.; Cloutier, S. Evolutionary origin of the segmental duplication encompassing the wheat GLU-B1 locus encoding the overexpressed Bx7 (Bx7OE) high molecular weight glutenin subunit. Theor. Appl. Genet. 2008, 116, 283-296. [CrossRef]

20. Geng, Y.; Pang, B.; Hao, C.; Tang, S.; Zhang, X.; Li, T. Expression of wheat high molecular weight glutenin subunit $1 \mathrm{Bx}$ is affected by large insertions and deletions located in the upstream flanking sequences. PLoS ONE 2014, 9, e105363. [CrossRef]

21. Cooper, J.K.; Stromberger, J.A.; Morris, C.F.; Bai, G.; Haley, S.D. End-Use Quality and Agronomic Characteristics Associated with the Glu-B1al High-Molecular-Weight Glutenin Allele in US Hard Winter Wheat. Crop Sci. 2016, 56, 2348-2353. [CrossRef]

22. Zhao, H.; Gao, C.; Song, W.; Zhang, Y.; Gao, D.; Zhang, X.; Zhao, L.; Yang, X.; Liu, D.; Song, Q. Quality differences between NILs of wheat variety Longmai 20 possessing HMW-GS 7 OE $+8^{*}$ and $17+18$. Cereal Res. Commun. 2020, 1-6. [CrossRef]

23. Wang, G.; Snape, J.; Hu, H.; Rogers, W. The high-molecular-weight glutenin subunit compositions of Chinese bread wheat varieties and their relationship with bread-making quality. Euphytica 1993, 68, $205-212$. [CrossRef]

24. Wang, X.; Zhang, Y.; Zhang, B.; Florides, C.G.; Gao, Z.; Wang, Z.; Zhang, X.; Wei, Y. Comparison of quality properties between high-molecular-weight glutenin subunits $5+10$ and $2+12$ near-isogenic lines under three common wheat genetic backgrounds. Cereal Chem. 2018, 95, 575-583. [CrossRef]

25. Hernández-Estrada, Z.J.; Rayas-Duarte, P.; Cárdenas, J.D.D.F. Creep recovery of wet gluten and high-molecular-weight glutenin subunit composition: Relationship with viscoelasticity of dough and breadmaking quality of hard red winter wheat. Cereal Chem. 2017, 94, 223-229. [CrossRef]

26. Payne, P.I.; Lawrence, G.J. Catalogue of alleles for the complex gene loci, Glu-A1, Glu-B1, and Glu-D1 which code for high-molecular-weight subunits of glutenin in hexaploid wheat. Cereal Res. Commun. 1983, 11, 29-35.

27. Courcoux, P.; Serot, T.; Larre, C.; Popineau, Y. Characterization and identification of wheat cultivars by multi-dimensional analysis of reversed-phase high-performance liquid chromatograms. J. Chromatogr. A 1992, 596, 225-232. [CrossRef]

28. Wang, S.; Yu, Z.; Cao, M.; Shen, X.; Li, N.; Li, X.; Ma, W.; Weissgerber, H.; Zeller, F.; Hsam, S.; et al. Molecular mechanisms of HMW glutenin subunits from $1 S(1)$ genome of Aegilops longissima positively affecting wheat breadmaking quality. PLOS ONE 2013, 8, e58947.

29. Peng, Y.; Yu, K.; Zhang, Y.; Islam, S.; Sun, D.; Ma, W. Two Novel Y-Type High Molecular Weight Glutenin Genes in Chinese Wheat Landraces of the Yangtze-River Region. PLoS ONE 2015, 10, e0142348. [CrossRef]

30. Yan, Y.; Hsam, S.; Yu, J.; Jiang, Y.; Zeller, F. Allelic variation of the HMW glutenin subunits in Aegilops tauschii accessions detected by sodium dodecyl sulphate, acid polyacrylamide gel and capillary electrophoresis. Euphytica 2003, 130, 377-385. [CrossRef]

31. Živančev, D.; Horvat, D.; Torbica, A.; Belović, M.; Šimić, G.; Magdić, D.; Đukić, N. Benefits and limitations of lab-on-a-chip method over reversed-phase high-performance liquid chromatography method in gluten proteins evaluation. J. Chem. 2015, 2015, 430328. [CrossRef] 
32. Rasheed, A.; Wen, W.; Gao, F.; Zhai, S.; Jin, H.; Liu, J.; Guo, Q.; Zhang, Y.; Dreisigacker, S.; Xia, X.; et al. Development and validation of KASP assays for genes underpinning key economic traits in bread wheat. Theor. Appl. Genet. 2016, 129, 1843-1860. [CrossRef]

33. Ravel, C.; Faye, A.; Ben-Sadoun, S.; Ranoux, M.; Dardevet, M.; Dupuits, C.; Exbrayat, F.; Poncet, C.; Sourdille, P.; Branlard, G. SNP markers for early identification of high molecular weight glutenin subunits (HMW-GSs) in bread wheat. Theor. Appl. Genet. 2020, 133, 751-770. [CrossRef]

34. Liu, L.; Wang, A.; Appels, R.; Ma, J.; Xia, X.; Lan, P.; He, Z.; Bekes, F.; Yan, Y.; Ma, W. A MALDI-TOF based analysis of high molecular weight glutenin subunits for wheat breeding. J. Cereal Sci. 2009, 50, 295-301. [CrossRef]

35. Shin, D.; Cha, J.K.; Lee, S.M.; Ko, J.M.; Lee, J.H. Validation and selection of functional allele-specific molecular markers to analyze High-Molecular-Weight glutenin subunit composition in wheat. Korean J. Breed. Sci. 2020, 52, 235-243. [CrossRef]

36. Živančev, D.R.; Torbica, A.M.; Tomić, J.M.; Janić Hajnal, E.P.; Belović, M.M.; Mastilović, J.S.; Kevrešan, Ž.S. Effect of Climate Change on Wheat Quality and HMW Glutenin Subunit Composition in the Pannonian Plain. Cereal Chem. 2016, 93, 90-99. [CrossRef]

37. Rhazi, L.; Bodard, A.L.; Fathollahi, B.; Aussenac, T. High throughput microchip-based separation and quantitation of high-molecular-weight glutenin subunits. J. Cereal Sci. 2009, 49, 272-277. [CrossRef]

38. Uthayakumaran, S.; Batey, I.L.; Wrigley, C.W. On-the-spot identification of grain variety and wheat-quality type by Lab-on-a-chip capillary electrophoresis. J. Cereal Sci. 2005, 41, 371-374. [CrossRef]

39. Uthayakumaran, S.; Listiohadi, Y.; Baratta, M.; Batey, I.L.; Wrigley, C.W. Rapid identification and quantitation of high-molecular-weight glutenin subunits. J. Cereal Sci. 2006, 44, 34-39. [CrossRef]

40. Balázs, G.; Tömösközi, S.; Harasztos, A.; Németh, V.; Tamás, Á.; Morgounov, A.; Belan, I.; Ma, W.; Békés, F. Advantages and Limitation of Lab-on-a-chip Technique in the Analysis of Wheat Proteins. Cereal Res. Commun. 2012, 40, 562-572. [CrossRef]

41. Bradová, J.; Matějová, E. Comparison of the results of SDS PAGE and chip electrophoresis of wheat storage proteins. Chromatographia 2008, 67, 83-88. [CrossRef]

42. Rasheed, A.; Safdar, T.; Gul-Kazi, A.; Mahmood, T.; Akram, Z.; Mujeeb-Kazi, A. Characterization of HMW-GS and evaluation of their diversity in morphologically elite synthetic hexaploid wheats. Breed. Sci. 2012, 62, 365-370. [CrossRef] [PubMed]

43. Van den Broeck, H.C.; America, A.H.; Smulders, M.J.; Bosch, D.; Hamer, R.J.; Gilissen, L.J.; van der Meer, I.M. A modified extraction protocol enables detection and quantification of celiac disease-related gluten proteins from wheat. J. Chromatogr. B 2009, 877, 975-982. [CrossRef]

44. Hlozáková, T.K.; Gregová, E.; Šliková, S.; Gálová, Z.; Chňapek, M.; Drábeková, J. Determination of HMW-GS in wheat using SDS-PAGE and Lab-on-chip methods. Potravin. Slovak J. Food Sci. 2019, 13, 477-481. [CrossRef]

45. Nakamura, H.; Sasaki, H.; Hirano, H.; Yamashita, A. A high molecular weight subunit of wheat glutenin seed storage protein correlates with its flour quality. Jpn. J. Breed. 1990, 40, 485-494. [CrossRef]

46. He, Z.H.; Liu, L.; Xia, X.C.; Liu, J.J.; Peña, R.J. Composition of HMW and LMW glutenin subunits and their effects on dough properties, pan bread, and noodle quality of Chinese bread wheats. Cereal Chem. 2005, 82, 345-350. [CrossRef]

Publisher's Note: MDPI stays neutral with regard to jurisdictional claims in published maps and institutional affiliations.

(C) 2020 by the authors. Licensee MDPI, Basel, Switzerland. This article is an open access article distributed under the terms and conditions of the Creative Commons Attribution (CC BY) license (http://creativecommons.org/licenses/by/4.0/). 